\title{
Smallholder Farmers' On and Off-Farm Gendered Responses to Climate Variability in Southern Rural Ghana
}

\author{
Divine Odame Appiah ${ }^{1 *}$, Ismail 0 Azeez $^{2}$ and Lois Antwi Boadi ${ }^{3}$ \\ ${ }^{1}$ Department of Geography and Rural Development, Kwame Nkrumah University of \\ Science and Technology, Ghana \\ ${ }^{2}$ Department of Forest Resources Management, University of Ibadan, Nigeria \\ ${ }^{3}$ Regional Institute of Population Studies (RIPS), University of Ghana, Legon
}

\author{
Research article \\ Volume 3 Issue 4
}

Received Date: September 11, 2019

Published Date: October 15, 2019

DOI: $10.23880 /$ jenr-16000173

*Corresponding author: Divine Odame Appiah, Department of Geography and Rural Development, Kwame Nkrumah University of Science and Technology, Kumasi, Ghana, Tel: +233267979012; Email: dodameappiah@yahoo.com

\section{Abstract}

Smallholder farmers may or may not have access to resources they may need for sustainable cultivation. With climate variability differential impacts, farmers may adopt measures on the farm and off the farm to better cope with the effects of climate variability. This paper examines the gendered differential responses to climate variability in the Offinso Municipality in the Ashanti Region of Ghana. Using a sample of 300 respondents from six farming communities, primary data was collected and analyzed with the use contingency tables, frequencies and chi-square tests of association in the SPSS v.16 for Windows applications. Results indicated that both sexes demonstrated different levels of knowledge of climate variability and adopted different strategies to better adapt to the effects of climate variability per their social constructs. The on-farm adaptation methods were similar but the off-farm adaptation measures differed; as the women did not earn higher incomes compared to their male counterparts, who had better alternative income earning avenues than their female counterparts. Women's access to and control of productive resources such as land should be enhanced at par with their male counterparts.

Keywords: Gendered Responses; On-Farm; Off-Farm; Climate Variability; Offinso; Ghana

\section{Introduction}

Climate variability and climate change may address some of the world issues on food security, but may also pose bigger threats, if households lack the capacity to adapt [1]. Among the poor regions around the world to be affected, sub-Sahara Africa contains about $63 \%$ of the world's most vulnerable [2,3]. This is because the region lacks financial, institutional and technological capacity to deal with the negative impacts which climate variability and change pose [4]. Other studies though have shown that not only climatic factors aid in aggravating poverty levels of African rain-fed agricultural farmers, but there may also be other non-climatic factors such as gender $[3,5]$. These non-climatic factors may exacerbate poverty 
levels of smallholder farmers at a faster rate than the climatic factors would.

The impacts of climate change may determine the adaptation strategies of individuals, and also by the gender attribution. As these impacts determine the level of vulnerability and vice versa, it is important individuals affected, respond by virtue of their, with the available resources at their disposal [6]. Vulnerability though is context specific as it involves some form of social (nonclimatic) and environmental conditions [4]. Gender as a social construct could therefore put the marginalized in society at a disadvantage, especially the poor.

Climate variability and climate change has detrimental effects on rural smallholder farmers whose farm sizes are generally small holdings, up to five hectares and have their livelihoods solely dependent on rain-fed agriculture. As frequent and prolonged droughts characterize the phenomenon, crop yield reduction and food insecurity would affect economies like Ghana [2]. Consequently, not all smallholder farmers would face similar impacts as studies show that female smallholder farmers would face more impacts than their male counterparts [7]. An imbalance of power relations between men and women in sub-Saharan Africa puts women at a disadvantage although the knowledge of women could be used in productive areas [4]. Such knowledge of women shapes their adaptation efforts, which over the years have been noted to be more sustainable, compared to male smallholder farmers.

Women in sub-Saharan Africa lack access to formal education are poor and may generally have limited access to resources [4]. As adaptation strategies are shaped mostly by individual access to resources, adapting to climate variability would be difficult and women would be more vulnerable compared to their male counterparts. Although many researches have proven the extent of women's disadvantage in the face of climate variability and climate change $[8,9,5]$, gendered differentialsin the adaptation measuresof both male and female smallholder farmers have not been thoroughly studied in rural Ghana, specifically Offinso Municipal Assembly.

In Ghana, women constitute $52 \%$ of the agricultural labour force and also produce $70 \%$ of food crops [10]. This makes adaptation strategies more important as it could aid in formulating better gender-based policies to aid female farmers in increasing productivity. These strategies could be adopted for the benefit of their farms (on-farm) and may be used to retain soil fertility for the continuous harvest of their farm products [11]. Another intervention would help the farmers as the threat posed by climate change increases. With this, the smallholder farmers could find measures that could be beneficial in terms of an in-flow of money when their farms do not produce enough to sustain them.

Most of the research that identified the adaptation strategies used by smallholder farmers did not disaggregate their findings on the basis of gender. In the few instances of gender consideration, the relative gendered adaptation strategies were not very clear among rural smallholder farmers, particularly in developing countries. As male smallholder farmers could have better on-farm and off-farm adaptation strategies compared to their female counterparts, it is imperative to compare the strategies and options available to both sex and solutions identified for the benefit of female smallholder farmers, particularly, who may more vulnerable to the impacts of climatic change than the male smallholder counterparts [12]. The purpose of this study is to examine the on-farm adaptation strategies as well as the off-farm adaptation strategies employed by farmers to better find effective ways for farmers to cope with climate variability and change in order to aid them in living sustainably from a gendered perspective.

\section{Research Methods}

\section{Profile of the Study Area}

The Offinso Municipal Assembly consists of a population of 76,895 . Of this, $48 \%$ are males and $52 \%$ are females [13]. The municipality lies between Latitudes $6^{\circ} 95^{\prime} \mathrm{N}$ and $7^{\circ} 15^{\prime} \mathrm{N}$, and Longitudes $1{ }^{03} 5^{\prime} \mathrm{W}$ and $1050^{\prime} \mathrm{W}$ which puts it in the North-western part of Ashanti Region (Figure 1). A relatively high percentage of the people engage in agricultural activities (68\%) possibly due to the larger percentage (72\%) of the Municipal being rural [13]. It is bounded by Offinso North District to the north, EjuraSekyedumase Municipal to the East, Sekyere South in the South-East and Atwima Nwabiagya and Ahafo-Ano South Districts to the West. It has a total land area of $585.7 \mathrm{~km}^{2}$. Temperature is fairly uniform ranging from $21^{\circ} \mathrm{C}$ to $32^{\circ} \mathrm{C}$. The district has an average annual rainfall of $103.8 \mathrm{~cm}$, with a double maxima rainfall from April to June and September to October as the rainfall season whiles August to September, and December through February is the dry season. Agriculture in the Municipal is mostly rain-fed.

Six communities namely; Ayensua, Amoowi, Adukrom, Asuboi, Abofour and Namong were purposively selected, 
based on their intensity of farming activities being practiced in the areas, from the municipal for the study. A total of 300 respondents were inquired from for the purpose of the study. These communities were selected not only on the commonalities but also their apparent differences in socio-economic and cultural characteristics.

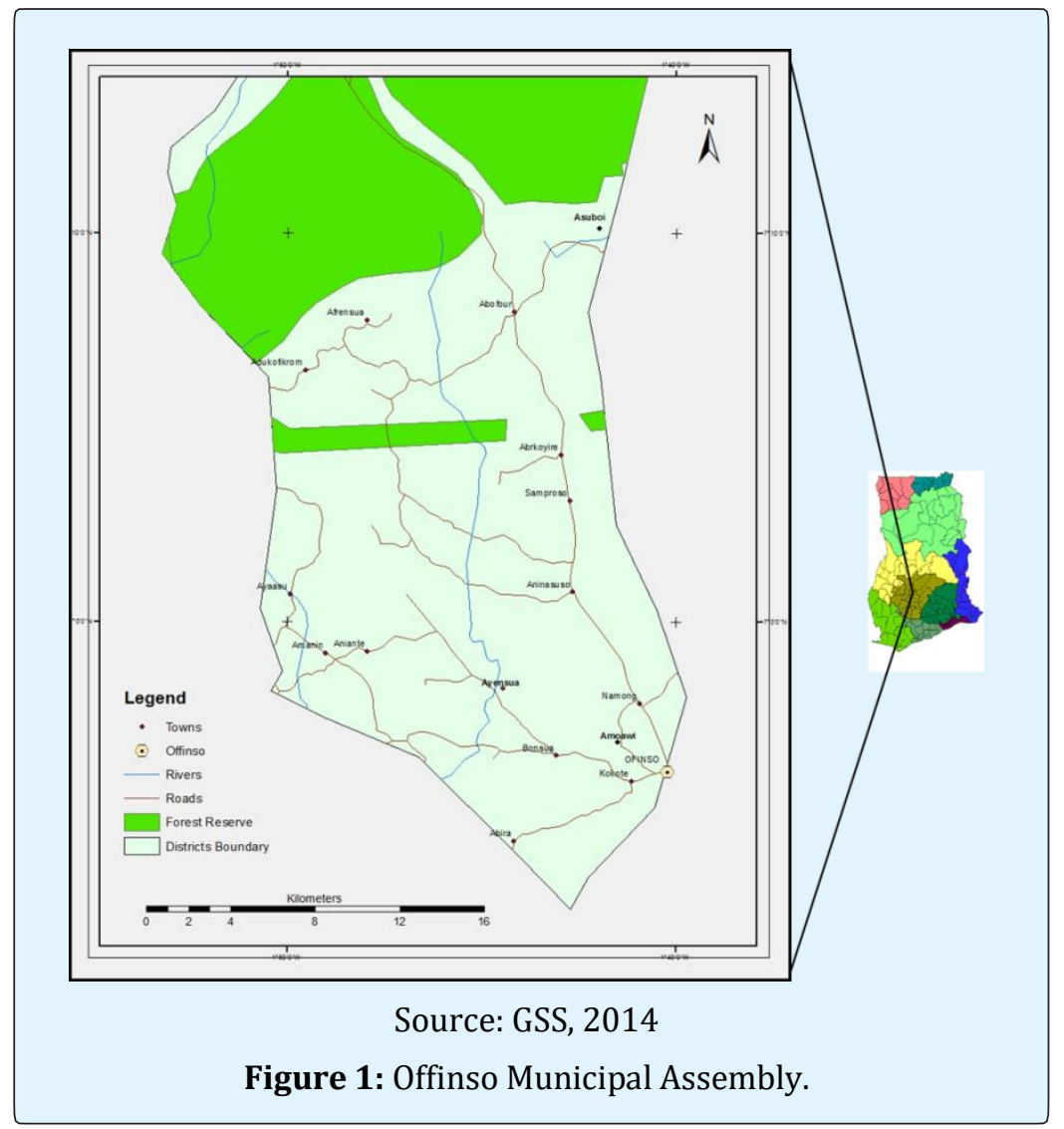

\section{Research Design and Method of Data Analysis}

This paper adopted a cross-sectional research design to conduct a survey of smallholder farmers in the Offinso Municipal. Primary data were collected (using questionnaire and focus group discussions) from the selected communities. Key issues addressed included; socio-demographic characteristics, on-farm adaptation measures and off-farm adaptation measures of farmers to climate variability and change. Secondary data were also reviewed from relevant peer-reviewed articles and the Municipal Assembly, for a contextual desk study. A probability simple random sampling technique was used to select 300 farmers from the six out of 24 communities in the Municipal. This was adopted because of the homogenous socioeconomic and cultural characteristics of the agrarian communities.

Cross-tabulation, frequency and Pearson Chi-square test of association were used to analyze the relationships between the variables and the gendered differentials between the sex, impacts and responses to the climate variability from the data collected, with the help of the Statistical Package for Service Solution (SPSS) v.16 for windows applications. The analyzed results were presented in the form of graphs and charts using Excel and Word applications in Microsoft.

\section{Results and Discussion}

\section{Socio-Demographic Characteristics and Climate Change}

Adaptation measures by farmers to cope with climate change depend on the impact as well as the resources at their disposal [6]. The study, for this reason, solicited the responses of a sample of 300 from Abofour, Adukro, Ayensua, Asuboi, Amoowi and Namong communities. The male smallholder farmers made up $67 \%$ of the 


\section{Journal of Ecology \& Natural Resources}

'respondents and the remaining 33\% were female smallholder farmers. The age range of the respondents was between 20 and 76 and above. Between 46-55 years was the largest representation of about $30 \%$ representation, followed by 36- 45 years (26\%), 56-65 years (20\%), 20 -35 years (13\%), 66-75 years (eight percent) and the least ages recorded in 76 and above $(3 \%)$.

The level of formal education of smallholder farmers could determine their ability to adapt as well as their coping strategies [14-16]. In Ghana, people who have been able to complete JHS/JSS are relatively higher than other levels of formal education [10]. The percentage of respondents who had been able to complete JHS/ Middle School formed 58\%, the highest coming from the ages between 46- 55 years (22\%) were in line with the national trend. This was followed by respondents who had never attended school (18\%), 28\% of which were females against $14 \%$ males. In Ghana, there is a marked difference as there are more females than males who have been to school [10]. The ages and educational statuses of the respondents are indicated in Table 1.

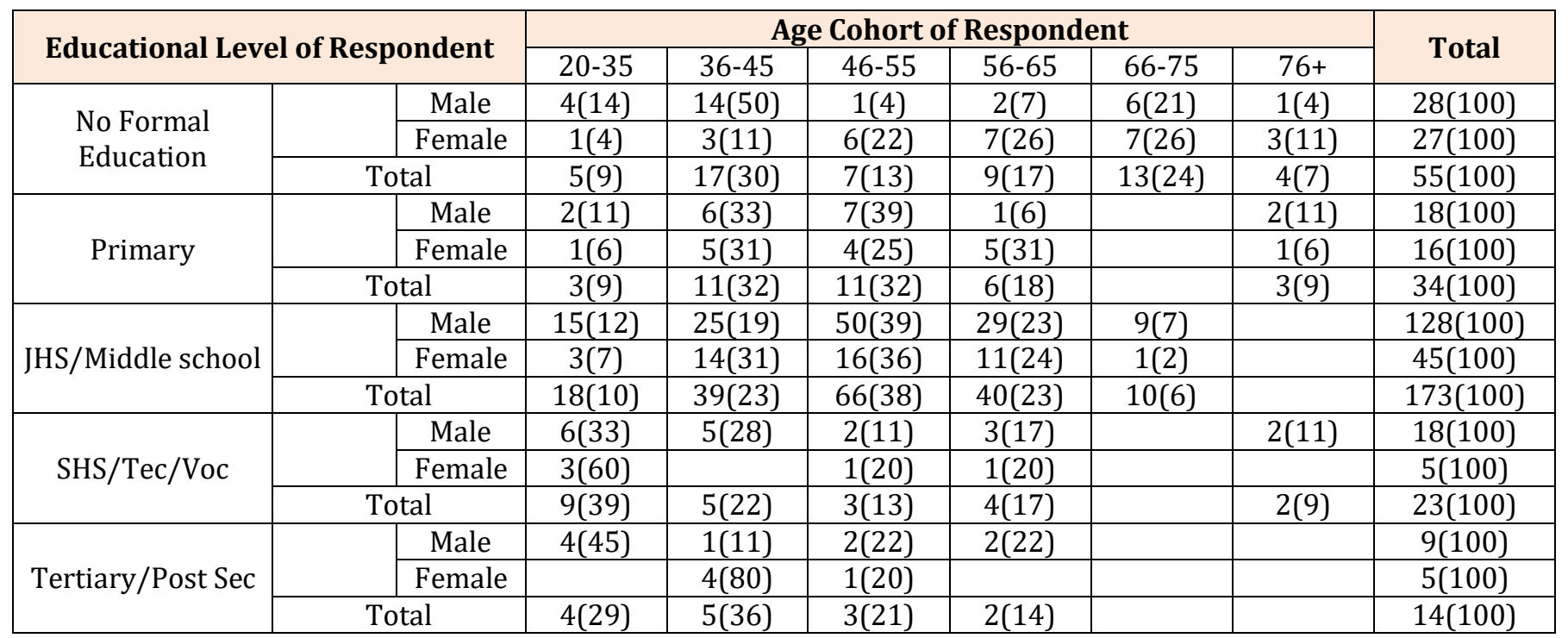

Source: Authors fieldwork, 2015

Table 1: Level of Formal Education by Age and Sex; Percentages in Parenthesis.

A Pearson chi square test between formal education among the different sexes and within the different age groups was very significant for respondent farmers who had never been to school. It was very significant at 0.05 levels with $\mathrm{p}=0.006$, the $\chi^{2}=16.331$ at 5 degrees of freedom, with the strength of dissociation by the Cramer's $\mathrm{V}$ of 0.545 . This implies that the age of a respondent who had never been to school was highly determined by the sex of the individual. This agrees with findings which show that among the different age groups, sex has been a determining factor in the level of formal education [17].

Out of the total number of respondent farmers, $69 \%$ and $91 \%$ of the females and males respectively were married. As men tend to marry even at advanced ages compared to women [18], they formed the least percentages in the divorced and widowed categories (Table 2). In some cases, consulting a spouse concerning the activities to undertake on and off the farm could lead to better adaptation strategies [19]. As the married male respondent farmers outnumber the females, it is likely that they would have better adaptation strategies.

A Pearson chi-square test of association between the sex of respondent and the marital status of the respondent was significant at 0.05 levels with a $p<0.001$. The $\chi^{2}=36.376$ at 3 degrees of freedom, with the strength of dissociation by the Cramer's V of 0.363 . This implies in this case that the men could better cope with the effects of climate variability and change as they could be aided by their partners compared to their unmarried counterparts.

As smallholder farmers, higher percentages of both males (96\%) and females (97\%) engaged in farming activities as a main occupation. There were also noted diversifications in their secondary occupations (Figure 2). 
The females were involved in petty trading (43\%), food vending (11\%) dressmaking (three percent), palm wine tapping (three percent), hairdressing (two percent) and teaching (one percent). The secondary sources of livelihood for the males differed as they were involved in petty trading (19\%), palm wine tapping (15\%), masonry (four percent), carpentry (five percent), food vending (two percent), dressmaking (two percent), charcoal production (one percent), teaching (two percent) and other menial jobs (six percent).

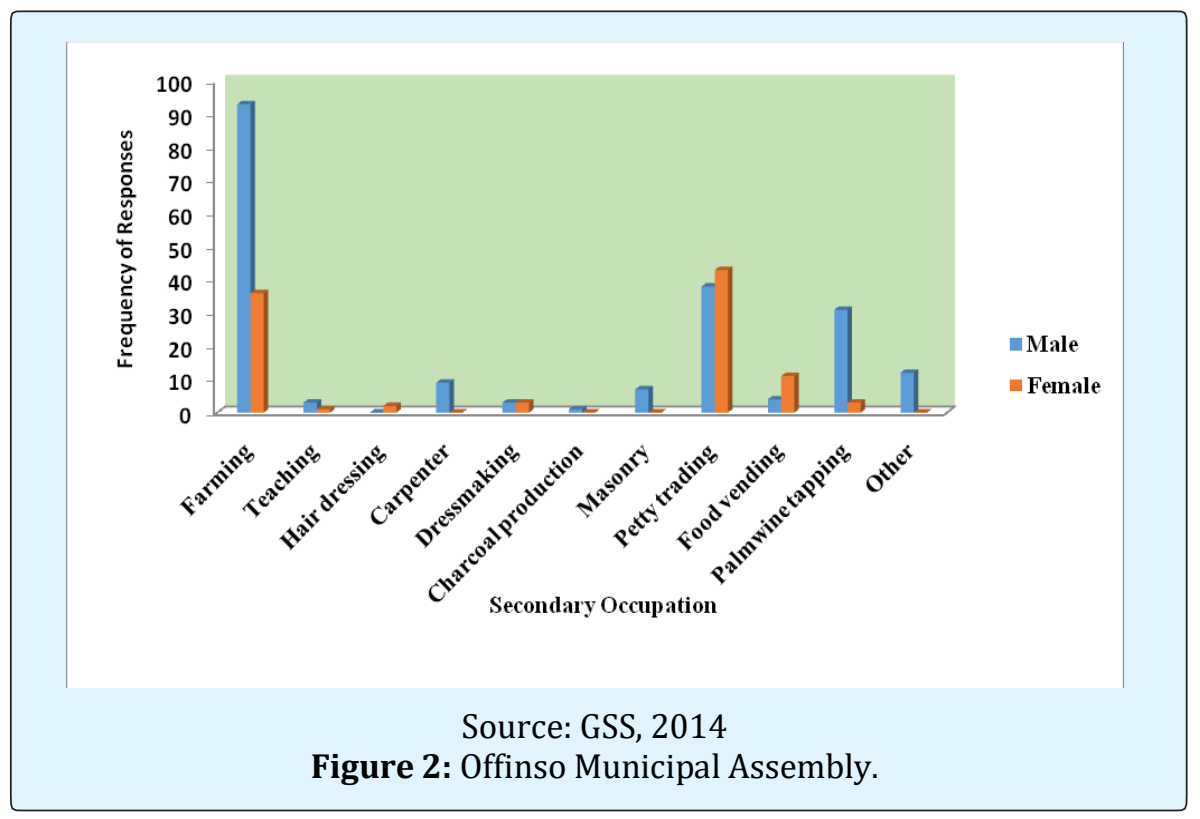

Men are usually placed in muscle-related jobs that earn them more than that of women as there is the perception that women cannot undertake such jobs [20]. In such a situation, men earn more than women and could expand their farming activities [14]. As income is a determinant of a smallholder farmer's adaptive capacity, many of the respondent male smallholder farmers would get a higher income [21]. With fewer opportunities for women, poverty would be worsened and this could lead to unhealthy adaptation measures [22]. A Pearson chisquare test of association between the sex of the respondent and their occupations was significant at 0.05 levels with a $\mathrm{p}<0.001$. The $\chi^{2}=55.663$ at 10 degrees of freedom, with the strength of dissociation by the Cramer's $\mathrm{V}$ of 0.430 .

\section{On-Farm Adaptation Strategies}

Involvement in rain-fed agriculture in the Offinso Municipal has led to the vulnerability of both male and female smallholder farmers. As climate variability worsens, female smallholder farmers are expected to experience the worst of the impacts as their alternative income sources are limited as compared to their male counterparts [3]. In some developing countries, men and women in different communities have successfully utilized their knowledge of the environment to mitigate climate variability [23]. With this knowledge, they are able to adapt as well as mitigate. Adaptation though differs for both sexes, especially in the Offinso Municipal Assembly, as both the male and female respondents have different resources, as a result of their social constructs, at their disposal.

The smallholder farmers from the selected communities had responded to climate change in varying ways. The response showed that due to climate variability, the size and location of farms of some of the respondents had been changed and even water for irrigation had been introduced in a few cases. On the size of the farm, $15 \%$ males and eight percent females had acquired between 13 to over 16 acres of land (Table 2) and $63 \%$ of the males and $71 \%$ of the females had located their farms to water sources to better withstand the effects of climate variability. In terms of irrigation, $43 \%$ of the males and $39 \%$ of the females were now using water for irrigation (Table 3). 


\section{Journal of Ecology \& Natural Resources}

\begin{tabular}{|c|c|c|c|c|c|c|c|c|c|}
\hline & & \multicolumn{9}{|c|}{ Size of the farm } & \multirow{2}{*}{ Total } \\
\hline & & Less than 1 acre & $1-3$ acres & $4-6$ acres & $7-9$ acres & $10-12$ acres & $\begin{array}{c}13-15 \\
\text { acres }\end{array}$ & $16+$ acres & \\
\hline \multirow{2}{*}{ Sex } & Male & $4(2)$ & $61(30)$ & $63(31)$ & $19(9)$ & $24(12)$ & $5(3)$ & $25(12)$ & $201(100)$ \\
\cline { 2 - 10 } & Female & $6(6)$ & $36(37)$ & $32(32)$ & $12(12)$ & $5(5)$ & $3(3)$ & $5(5)$ & $99(100)$ \\
\hline \multicolumn{2}{|c|}{ Total } & $\mathbf{1 0}(3)$ & $\mathbf{9 7}(\mathbf{3 2})$ & $\mathbf{9 5 ( 3 2 )}$ & $\mathbf{3 1 ( 1 0 )}$ & $\mathbf{2 9}(10)$ & $\mathbf{8 ( 3 )}$ & $\mathbf{3 0}(\mathbf{1 0})$ & $\mathbf{3 0 0}(\mathbf{1 0 0})$ \\
\hline
\end{tabular}

Table 2: Size of Farm by Sex; Percentages in Parenthesis.

Although 25\% females owned land against 28\% males, with $80 \%$ of respondents practicing mixed cropping, adaptation practices were quite effective for the smallholder farmers. Among the on-farm adaptation strategies practiced by the farmers, $17 \%$ had extended their farmlands, $13 \%$ of which were women (Figure 3). The use of agrochemicals was limited among the respondent farmers although it has been noted to be the highest on farm adaptation practice recorded by both sexes in some cases [24]. Out of the $36 \%$ respondents making use of agro-chemicals, $41 \%$ were females.
With less income to acquire more farmlands, the results from the study showed that the female smallholder farmers mostly changed the types of crops they cultivated and this was represented by $18 \%$ females against $16 \%$ of the males. This could have implications for the women especially if the new crops cultivated are not able to earn them as much as previous crops. Poverty for these female smallholder farmers would thus be worsened [7].

\begin{tabular}{|c|c|c|c|c|c|}
\hline \multirow{2}{*}{\multicolumn{3}{|c|}{ Use of water for irrigation }} & \multicolumn{2}{|c|}{ Location of farm in relation to water source } & \multirow{3}{*}{$\begin{array}{c}\text { Total } \\
81(100)\end{array}$} \\
\hline & & & \multirow{2}{*}{\begin{tabular}{|c|}
$\begin{array}{c}\text { Located near water } \\
\text { source }\end{array}$ \\
$78(96)$ \\
\end{tabular}} & \multirow{2}{*}{$\begin{array}{c}\text { Not located near water } \\
\text { source }\end{array}$} & \\
\hline \multirow{3}{*}{ Yes } & \multirow{2}{*}{ Sex } & Male & & & \\
\hline & & Female & $37(100)$ & - & $37(100)$ \\
\hline & \multicolumn{2}{|c|}{ Total } & $115(97)$ & $3(3)$ & $118(100)$ \\
\hline \multirow{3}{*}{ No } & \multirow{2}{*}{ Sex } & Male & $44(69)$ & $20(31)$ & $64(100)$ \\
\hline & & Female & $31(82)$ & $7(18)$ & $38(100)$ \\
\hline & & & $75(74)$ & $27(26)$ & $102(100)$ \\
\hline \multirow{3}{*}{ Not applicable } & \multirow{2}{*}{ Sex } & Male & $4(9)$ & $41(91)$ & $45(100)$ \\
\hline & & Female & $2(11)$ & $17(89)$ & $19(100)$ \\
\hline & \multicolumn{2}{|c|}{ Total } & $6(9)$ & $58(91)$ & $64(100)$ \\
\hline
\end{tabular}

Table 3: Location of Farm and Use of Water for Irrigation Percentages in Parenthesis.

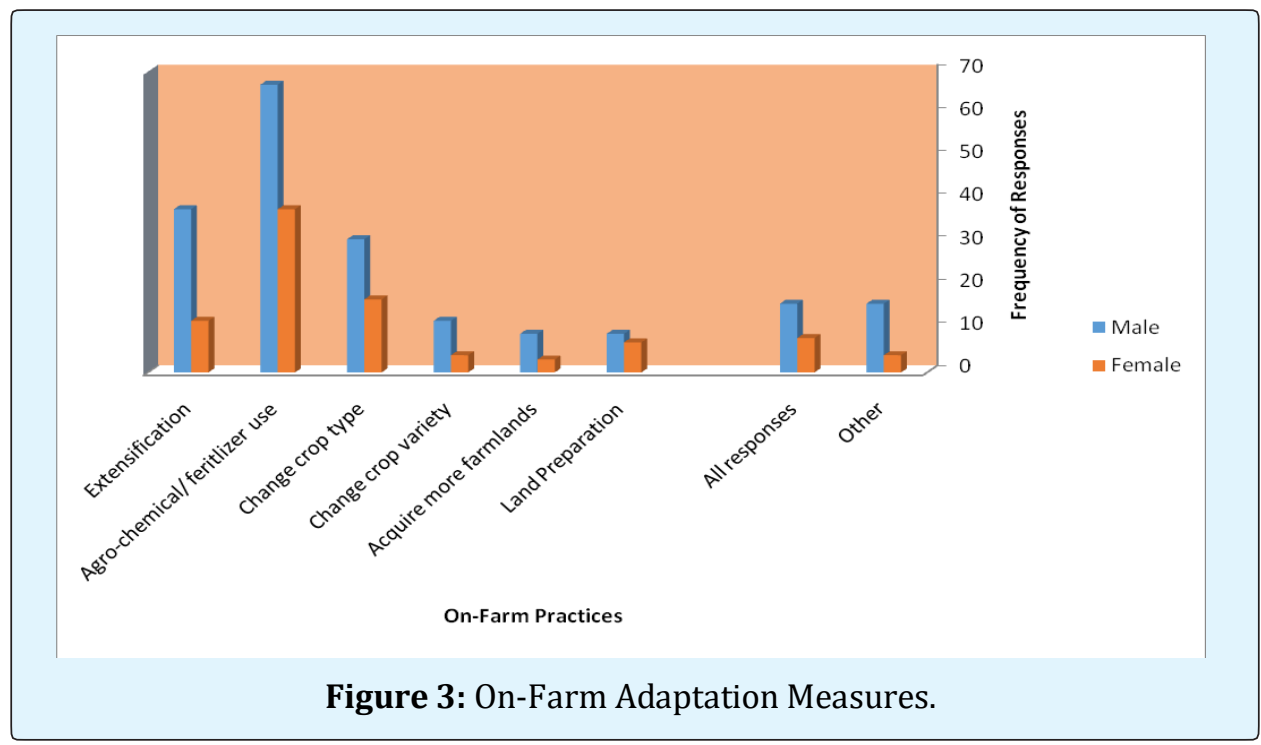




\section{Journal of Ecology \& Natural Resources}

Other important but not utilized on-farm adaptation practices by the farmers were to prepare land to conserve soil moisture (six percent) as well as acquire more farmlands which were recorded among five per cent of the males and three percent of the females. Such a case has been noted in other parts of Africa [25,26]. Due to the diversified income sources of the males which enable them to acquire more lands, they become better off than their female counterparts.

When the on- farm adaptation practices failed, the farmers tried to find other measures such as relocating the farm closer to a water source. Out of the $30 \%$ who had relocated their farms, $32 \%$ were females and $29 \%$ were males. This showed the extent to which the female farmers were willing to save their source of livelihood as they lacked other sources of income [27].

\section{Off-Farm Income Generating Activities}

Although on-farm adaptation practices had been effective to $80 \%$ of the farmers, they buttressed these practices with off-farm income generating activities, to better cope with climate variability and change. Petty trading was a high income generating activity as it engaged about $23 \%$ of the farmers, $37 \%$ of which were females against $17 \%$ of the males. Trading is a female dominated activity and so most female farmers were bound to engage in it [18]. The activity was followed by Livestock rearing which occupied $19 \%$ of the females and $21 \%$ of the males. About $35 \%$ of the farmers did not have any off-farm income generating activity to engage in and so solely depended on agriculture. $26 \%$ of which were females and $39 \%$ of them, males. Other menial activities mostly done by the males included chainsaw operation, fashion designing, carpentry, Non-Timber forest products collection, food vending and masonry. The Pearson chisquare test of association was significant at 0.05 levels with a $p=0.003$. The Pearson chi-square test of association $\chi^{2}=26.195$ at 10 degrees of freedom, with the strength of dissociation by the Cramer's V of 0.305 .

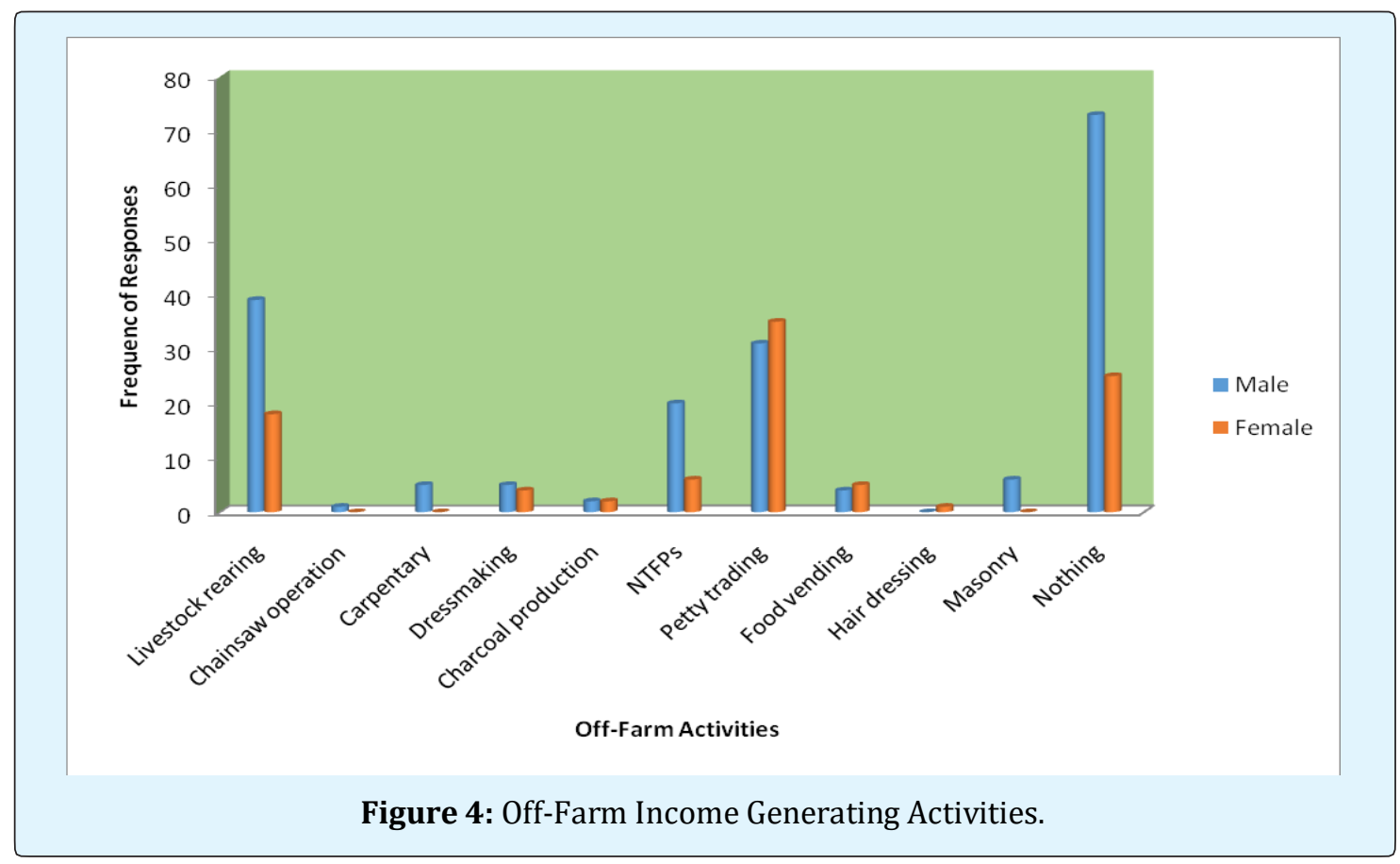

From figure 4, the once dominated female ventures were increasingly being taken over by the males with the exception of petty trading. The sex of the respondents determined to some extent their off farm adaptation strategies and thus put women at a disadvantage in the Offinso Municipal. This has also been the case in some countries $[28,29]$. To formulate better strategies therefore is to engage both sexes in activities that could reduce the impacts of climate change as well as aid them in formulating better adaptation strategies. 


\section{Conclusion and Recommendation}

The paper has espoused the gendered differential responses to the vagaries of climate variability and climate change in the Offinso Municipal in the Ashanti region of Ghana. From a mixed methods approach, both quantitative data obtained from questionnaires administered to 300 male and female respondents from six agrarian communities, were analyzed using crosstabulation and chi-squared tests of association all embedded in the SPSS v.16 for Windows application.

The results revealed that traditionally, men and women use their knowledge of climate variability and change to formulate adaptation strategies. This study delved into the on-farm adaptation as well as off-farm adaptation strategies of smallholder farmers from a gendered perspective. On the farms, females coped better although they did not have larger farm sizes. Yet more females had located their farms closer to water sources although most of them did not use the water when the rains fail. Even though the males could acquire more lands due to their diversified incomes, female smallholder farmers still engaged in sustainable adaptation strategies as they formed a lower percentage in the use of agrochemicals on their farms. Off-farm adaptation strategies by the male farmers were more effective as compared to their female counterparts as they had a wider range of job opportunities to engage in when their crops failed.

Government could improve women's livelihoods and strengthen their adaptation capacity by ensuring women's control and ownership of resources (such as land, livestock, property and income opportunities) could aid the women and give them better coping strategies to climate change. The use of extension officers in the municipality could also be helpful to the smallholder farmers who may lack the necessary knowledge about climate change and the various ways to cope with it.

\section{Acknowledgement}

This research is supported by funding from the Department for International Development (DfID) under the Climate Impact Research Capacity and Leadership Enhancement (CIRCLE) programme, to which the authors are most grateful. We also thank the Department of Geography and Rural Development, Kwame Nkrumah University of Science and Technology, Ghana and the department of Forest Resources Management, University of Ibadan, Nigeria for their logistical support. We thank Bernice Adu-Boahen for proof-reading the manuscript for language and grammatical coherence. We finally thank the anonymous reviewers for their constructive critique of this paper.

\section{References}

1. Ji-kun H (2014) Climate Change and Agriculture: Impact and Adaptation 13(1): 1-17.

2. Haysom L (2014) 'Gender and climate change'. Agenda 28(3): 1-2.

3. World Bank (2014) Agriculture and Rural Development.

4. Eriksen S, O'Brien K, Rosentrater L (2008) Climate change in Eastern and Southern Africa: Impacts, vulnerability and adaptation, University of Oslo, pp: 27.

5. Chianu J, Ajani NI, Chinua JN (2008) Livelihoods and rural wealth distribution among farm households in western Kenya: Implications for rural development, poverty alleviation interventions and peace. African J Agri Res 3(7): 455-464.

6. Hassan R, Nhemachena C (2008) Determinants of African farmer's strategies for adapting to climate change: Multinomial choice analysis. African J Agri Res Econom 2(1): 83-104.

7. Roehr U (2007) Gender, climate change and adaptation. Introduction to the gender dimensions. Background Paper prepared for the Both Ends Briefing Paper Adapting to climate change: How local experiences can shape the debate, pp: 11.

8. Points E (2014) United Nations Framework Convention on Climate Change (UNFCCC) decisions and conclusions: 1-58.

9. Habtezion S (2013) Overview of linkages between gender and climate change. Policy Brief, United Nations Development Programme, New York, pp: 6.

10. Ghana Statistical Service (2010) The 2010 Population and Housing Census: Summary Report of Final Results. Accra: Ghana Statistical Service, pp: 1-117.

11. Uddin MN, Bokelmann W, Entsminger JS (2014) Factors affecting farmer's adaptation strategies to environmental degradation and climate change 


\section{Journal of Ecology \& Natural Resources}

effects: A farm level study in Bangladesh. Climate 2(4): 223-241.

12. Yavinsky RW (2013) Women more vulnerable than men to climate change. Population Reference Bureau. Washington, DC, 2009 pp: 1-58.

13. Ghana Statistical Service (2014) The 2010 Population and Housing CensusDistrict Analytical Report, Offinso Municipality pp: 1-72.

14. Komba C, Muchapondwa E (2012) Adaptation to climate change by smallholder farmers in Tanzania. Economic Research Southern Africa (ERSA). Working paper 299: 1-49.

15. Deressa TT, Hassan RM, Ringler C, Alemu T, Yesuf M (2009) Determinants of farmer's choice of adaptation methods to climate change in the Nile Basin of Ethiopia. Global Environ Change 19(2): 248-255.

16. Maddison DJ (2007) The perception of and adaptation to climate change in Africa. World Bank Policy Research, Working Paper 4308.

17. Below TB, Mutabazi KD, Kirschke D, Franke C, Sieber S, et al. (2012) Can farmer's adaptation to climate change be explained by socio-economic householdlevel variables?. Global Environ Change 22(1): 223235.

18. Ghana Statistical Service (2013) The 2010 Population and Housing Census Report: The Elderly in Ghana, pp 112.

19. Jiri O, Mafongoya P, Chivenge P (2015) Small holder Farmer Perceptions on Climate Change and Variability: A Predisposition for their Subsequent Adaptation Strategies. J Earth Sci Climat Change 6: 277.

20. Smith S, Choueiti M, Prescott A, Pieper K (2012) Gender Role \& Occupations: A Look at Character Attributes and Job-Related Aspirations in Film and Television. Greena Davis Institute on Gender in Media pp 46.
21. Eriksen S, Aldunce P, Bahinipati CS, Martins RDA, Molefe JI, et al. (2011) When not every response to climate change is a good one: Identifying principles for sustainable adaptation. Climate Development 3(1): 7-20.

22. Demetriades J, Esplen E (2008) The gender dimensions of poverty and climate change adaptation. Ids Bulletin 39(4): 24-31.

23. Lane R, McNaught $R$ (2009) Building gendered approaches to adaptation in the Pacific. Gender Development 17(1): 67-80.

24. Skinner E (2011) Gender and climate change: Overview report. Bridge pp: 1- 91.

25. Howden SM, Soussana JF, Tubiello FN, Chhetri N, Dunlop M, et al. (2007) Adapting agriculture to climate change. Proceed National Academy Sci 104(50): 19691-19696.

26. Rockstrom J, Kaumbutho P, Mwalley P, Temesgen M (2003) Conservation farming among small-holder farmers in E. Africa: Adapting and adopting innovative land management options. Conservation Agriculture 2: 459-469.

27. Sugden F, Silva SD, Clement F, Maskey-Amatya N, Ramesh V, et al. (2014) A framework to understand gender and structural vulnerability to climate change in the Ganges River Basin: lessons from Bangladesh, India and Nepal. IWMI Working Paper 159: 1-55.

28. Otzelberger A (2011) Gender-responsive strategies on climate change: recent progress and ways forward for donors. Institute of Development Studies: 1-58.

29. Djoudi H, Brockhaus M (2011) 'Is adaptation to climate change gender neutral? Lessons from communities dependent on livestock and forests in northern Mali'. International Forestry Review 13(2): 123-135. 